\title{
BILATERAL ANTERIOR DISLOCATION OF SHOULDER
}

Lamture D. $\mathrm{R}^{1}$, Dhaniwala N. S 2

\section{HOW TO CITE THIS ARTICLE:}

Lamture D. R, Dhaniwala N. S. "Bilateral Anterior Dislocation of Shoulder". Journal of Evolution of Medical and Dental Sciences 2014; Vol. 3, Issue 24, June 16; Page: 6654-6657, DOI: 10.14260/jemds/2014/2798

INTRODUCTION: Simultaneous Bilateral Anterior Dislocation of Shoulder (BADS) is very rare and is usually of traumatic origin. Here under a case of post traumatic BADS is reported due to its rarity.

MATERIALS \& METHODS: A 35years old male presented in the emergency department with complaints of severe pain and inability to move both the shoulders following assault by many persons and fall on ground. He attempted saving himself by lifting both his upper limbs in abduction and external rotation at shoulder. Examination revealed both his arms lying in abduction and external rotation and loss of rounded contour of shoulders. Humeral heads were palpable anteriorly in the subcoracoid location. Movements were painfully restricted and there was no neurovascular deficit in the limbs.

Radiographs of the shoulders showed BADS without any evidence of fracture in tuberosities or neck humerus. Dislocations were reduced by closed manipulation under general anesthesia using Kocher's maneuver and both his arms were immobilized in adduction and internal rotation for 04 weeks. The patient underwent gradual mobilizing exercises and was able to resume his routine activities after 03 months.

DISCUSSION: Unilateral shoulder dislocation is the most common major joint dislocation forming $85 \%$ of all dislocations. Of all shoulder dislocations $96 \%$ are anterior, 3\% are posterior and $1 \%$ inferior(1) and $15 \%$ of these are combined with greater tuberosity fracture.(4) The common mechanism of injury is forceful abduction and external rotation with an element of extension of shoulder. Anterior dislocation of shoulder may also occur in a violent contraction of the shoulder muscles or a direct blow on the back of the shoulder. Because of the position naturally adopted by the upper limb during a fall, unilateral anterior dislocation is common.

Bilateral shoulder dislocations are rare and almost always posterior.(2,3,4) It was first described in 1902 in a patient with muscular contraction due to camphor overdose. Bilateral dislocation of shoulder is common in epileptic cases but it is always posterior. (3) Most of the Bilateral dislocations are associated with fractures. About 30 cases of BADS have been reported till date of which 15 were of fracture dislocation. The associated fracture seen is fracture of greater tuberosity or a fracture in the neck humerus. Most were due to trauma but sports injuries, seizures, electrical shock, neuromuscular and psychiatric disturbances have been implicated as causative factors. $(5,6)$ Loss of control in water skiing,(7) forceful diving in water, ${ }^{(8)}$ bench press injury(9) weight lifting(10,11) and domestic fall(12) have also been reported to be responsible for bilateral anterior dislocation of shoulder. Aufranc reported the first bilateral anterior dislocation of shoulder following seizure.(13) $10 \%$ of documented bilateral anterior dislocations were diagnosed late. ${ }^{(14,15)}$ Cases of sequential bilateral dislocation of shoulder have also been described.(16)

The reported case sustained acute bilateral shoulder dislocation due to the classical mechanism of forced extension, abduction and external rotation while saving self from assault by 
many persons. He reported to the hospital immediately and was managed on the expected lines and had an uneventful recovery following reduction. Clinically the posterior dislocation is suspected on the absence of fullness anteriorly with gross restriction of external rotation at the shoulder. Radiograph of the shoulder in the axial position helps in the differentiation of posterior from the anterior dislocation.

CONCLUSION: Bilateral anterior dislocation of shoulder is not as rare as considered. The condition should be suspected and excluded in bilateral shoulder injury due to any cause. Differentiation from the commoner posterior type is essential.

\section{REFERENCES:}

1. Kumar K. S, O’Rourke S., Pillay JG. Hands Up: A case of bilateral inferior shoulder dislocation. Emerg Med J 2001; 18: 404-405.

2. Brown RJ. Bilateral dislocation of the shoulders. Injury 1984; 15:267-73.

3. Dunlop CC. Bilateral anterior shoulder dislocation; a case report and review of literature. Acta Orthop Belg. 2002; 68: 168-170.

4. Devalia KL, Peter VK. Bilateral post-traumatic anterior shoulder dislocation. J Postgrad Med. 2005: 51: 72-73.

5. Sharma L et al. Bilateral anterior dislocation of the shoulders with proximal humeral fractures: a case report. J Orthop Surg 2005; 13(3): 303-306.

6. Litchfield JC, Subhedar VY, Beevers DG, Patel HT. Bilateral dislocation of the shoulders due to nocturnal hypoglycemia. Postgrad Med J. 1988: 64: 450-452.

7. Segal D, Yablon IG, Lynch JJ, Jones RP. Acute bilateral anterior dislocation of the shoulders. Clin Orthop Relat Res. 1979; 140: 21-22.

8. Faycal Dlimi, Abdelkarim Rhanim, Abdou Lahlou et al. Bilateral anterior dislocation of the shoulders at the start of a back stroke competition. J Orthop Traumatol, 2012 March; 13(1): 4749.

9. Cresswell TR, Smith RB. Bilateral anterior shoulder dislocations in bench pressing: an unusual case. Br J Sports Med.1998; 32 (1): 71-72.

10. Maffulli N, Mikhail HM. Bilateral anterior glenohumeral dislocation in a weight lifter. Injury 1990; $21 ; 254-256$.

11. Adrian M. Moughty, Gerard O' Connor. Bilateral anterior shoulder dislocation. N Eng J Med $2012 ; 367$.

12. Nagi ON, Dhillon MS. Bilateral anterior fracture dislocation of the shoulders. J orthop Traumatol 1990; 4; 93-95.

13. N Lasaniano, G mouzopoulos. An undiagnosed bilateral anterior shoulder dislocation after a seizure, a case report. Cases j 2008; $1: 342$

14. Aufranc OE, Jones WN, Turner RH. Bilateral shoulder fracture dislocations. JAMA 1966 Mar 28; 195(13): 1140-1143.

15. Connor Read L, Bloch B, Brownlow h. A missed orthopaedic injury following a seizure; a case report. J Med case Reports 2007; 10: 20

16. Singh Sandeep, Kumar Sudhir. European journal of emerg Med 2005; 12(1): 33-35. 


\section{CASE REPORT}

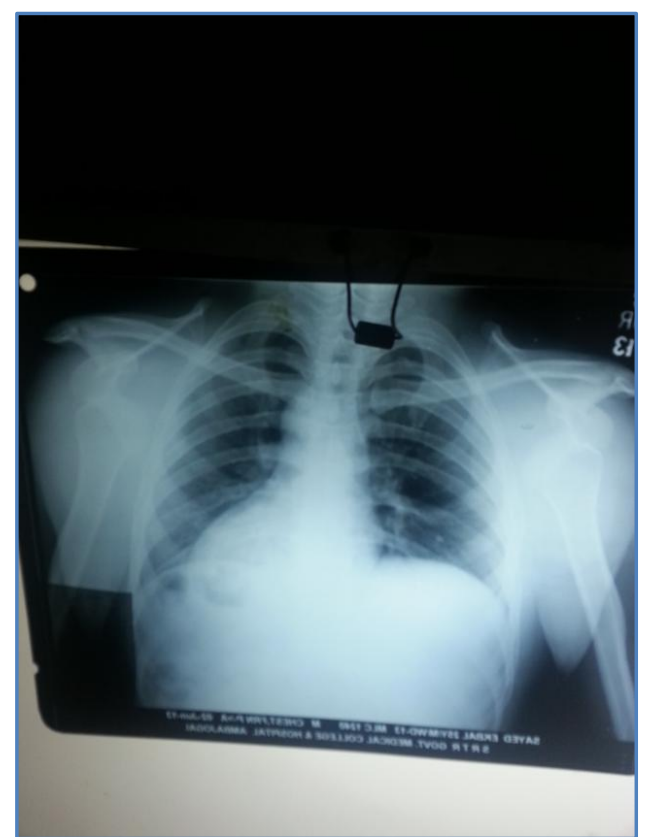

Picture-1 - X-rays showing dislocation of bilateral shoulder
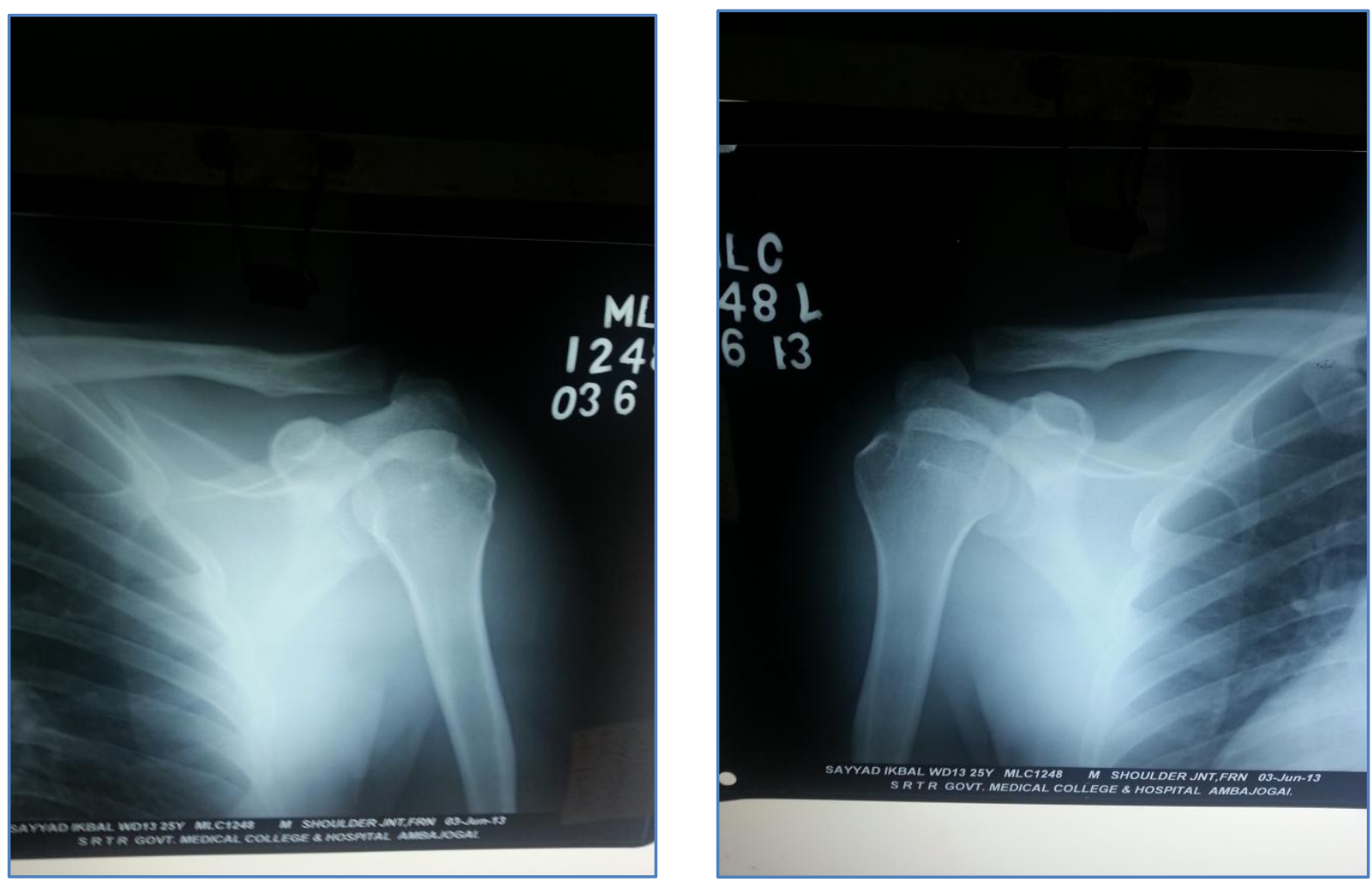

Picture 2, 3- X-rays reduced right and left shoulder respectively 


\section{CASE REPORT}

\section{AUTHORS:}

1. Lamture D. R.

2. Dhaniwala N. S.

\section{PARTICULARS OF CONTRIBUTORS:}

1. Assistant Professor, Department of Orthopaedics, S.R.T.R.G. Medical College, Ambajogai.

2. Professor, Department of Orthopaedics, S.R.T.R.G. Medical College, Ambajogai.
NAME ADDRESS EMAIL ID OF THE CORRESPONDING AUTHOR:

Dr. Lamture Deepak R,

Dept. of Orthopadeics,

S.R.T.R.G. Medical College,

Ambajogai Dist., Beed, PIN- 431517.

E-mail: dlamture@rediffmail.com

Date of Submission: 12/05/2014.

Date of Peer Review: 13/05/2014.

Date of Acceptance: 07/06/2014.

Date of Publishing: 12/06/2014. 